\title{
Managerial Effectiveness and Defense Mechanism Styles: a comparison of Different Level of Managers
}

\author{
Dr. Rishipal
}

\begin{abstract}
This questionnaire based cross-sectional study was conducted on 234 managers selected randomly on availability basis to find out the relationship between the managerial effectiveness and ego defense mechanisms adopted by the managers. Subjects chosen for study were working at different levels, i.e. junior, middle and senior level of management, in various public and private sector organizations in India. Ego defense mechanism styles among managers were assessed by using the Defense Style Questionnaire (DSQ-40). For testing the managerial effectiveness, Index of Managerial Effectiveness devised by Walter W. Hudson (1993) was used. Finding reveals that there is a negative and significant correlation between the managerial effectiveness of junior level managers and the immature styles of defense mechanism adopted by them. The correlation between managerial effectiveness of junior level managers and the mature styles of defense mechanisms adopted by them is positive and significant. Correlation between managerial effectiveness of junior level managers and the neurotic styles of defense mechanisms adopted by them was not significant. There was no significant correlation between the managerial effectiveness and immature styles and neurotic style of defense mechanism adopted by the middle level managers. But the correlation between the managerial effectiveness of the middle level managers and their styles of mature defense mechanism was positively significant. The managerial effectiveness of the senior managers and their styles of mature defense mechanism were positively and significantly correlated, whereas the managerial effectiveness of the senior managers and their styles of immature defense mechanism were negatively correlated. The correlation between senior manager's managerial effectiveness and neurotic style of defense mechanism was not found significant. There was significant difference between the means of mature style of defense mechanisms used by the managerially effective and non-effective managers. The difference between the means of immature style of defense mechanism used by the managerially effective managers and non-effective managers was also significant. But the difference between the means of neurotic style of defense mechanism adopted by the managerially effective managers and the managerially non-effective managers was not significant.
\end{abstract}

Keywords: managerial effectiveness, ego defense mechanisms, mature styles, immature styles, neurotic styles, managerially effective and managerially non-effective.

\section{Introduction}

\section{Ego Defense Mechanism}

Ego defense mechanism is a term coined by Freud in his psychoanalytical theory of personality. This term means the mental processes practiced by individuals to protect them from experiencing anxiety resulting from the perceived threat of internal or external stress to maintain self-esteem which prevent excessive levels of negative effect. In simple words defense mechanism may be understood as the unconscious processes which modifies or distorts the reality to protect an individual from awareness of their own unacceptable thoughts, impulses or wishes resulting into anxiety. Feelings of guilt, embarrassment and shame often accompany the feeling of anxiety. The anxiety is felt as an increase in mental tension and signal that the organism reacts to take the defensive action regarding the perceived danger. According to Freud, A. (1966) when anxiety becomes too irresistible, it is then the turn of the individual's ego to employ defense mechanisms to protect the self from unacceptable thoughts, impulses or wishes.

According to Freud (1923) human psyche/ personality may be divided into three sub-structures, first one is the id, which is the impulsive (and unconscious) part of our psyche which responds directly and immediately to the instincts. Id demands immediate satisfaction and when this happens we experience pleasure, when it is denied we experience irritation, displeasure or pain. The id is not affected by reality, logic or everyday life. On the contrary, it operates on the pleasure principle (Freud, 1920) which is the idea that every wishful impulse should be satisfied immediately, regardless of the consequences.

Ego is the second part of personality and it is "that part of the id which has been modified by the direct influence of the external world" (Freud 1923). The ego develops in order to mediate between the unrealistic id and the external real world. Ideally the ego works by reason whereas the id is chaotic and totally unreasonable. 
The ego operates according to the reality principle, working our realistic ways of satisfying the id's demands, often compromising or postponing satisfaction. Like the id, the ego seeks pleasure and avoids pain but unlike the id the ego is concerned with devising a realistic strategy to obtain pleasure. Freud made the analogy of the id being the horse while the ego is the rider. Often the ego is weak relative to the head-strong id and the best the ego can do is stay on, pointing the id in the right direction and claiming some credit at the end as if the action were its own. The ego has no concept of right or wrong; something is good simply if it achieves its end of satisfying without causing harm to itself or to the id (Freud, 1923).

The third part of individual's personality is superego which incorporates the values and morals of society which are learnt from one's parents, others and social code of behavior. The superego's function is to control the id's impulses, especially those which society forbids, such as sex and aggression. It also has the function of persuading the ego to turn to moralistic goals rather than simply realistic ones and to strive for perfection. The superego consists of two systems, the conscience and the ideal self. The conscience can punish the ego through causing feelings of guilt. Behavior which falls short of the ideal self may be punished by the superego through guilt. The super-ego can also reward us through the ideal self when we behave 'properly' by making us feel proud.

According to Freud, A (1966) Defense mechanisms work by distorting the id impulses into acceptable forms, or by unconscious or conscious blockage of these impulses. Defense mechanism is a type of adjustment for the wellbeing of the individual. This process of wellbeing is created and maintained for adjustment between id and superego by the ego to defend and protect the individual from feelings of guilt, embarrassment, anxiety, shame and other negative mental effects which are known as defense mechanism.

According to Vaillant (1977) There are various types of defense mechanisms such as: affiliation, coping, projection, compensation rationalization, denial, reaction formation repression, avoidance, identification, activism, intellectualization, omnipotence, regression, sublimation, displacement, anticipation, Conversion, altruism, resilience, humour, splitting, etc. These mechanisms are adopted by individuals to prevent them from the awareness of their own unacceptable thoughts, impulses or wishes resulting into anxiety. These defense mechanisms regulate the individual's inner psychological state through self-deception.

Vaillant (1977) has further limited these classifications into four categories like pathological, immature, neurotic and mature etc. Pathological defense mechanisms are psychotic (psychotics are the people passing through the abnormal state of mind, where they are experiencing complete loss of contact with reality) in nature and found in dreams and throughout childhood. The mechanisms included under this category are delusional projection, Conversion, denial, distortion, splitting, and extreme projection. Immature type of mechanisms is found in adults and these mechanisms help to reduce distress and anxiety initiated by the uncomfortable reality. These types of defenses are dominant in the state of major depression and personality disorders. Excessive use of such defenses is seen as socially undesirable, so why known as 'immature'. Excessive use of immature defense mechanism always leads to serious problems in a person's ability to adjust with self and environment. Immature mechanisms include acting out, fantasy, idealization, passive aggression, projection, projective identification and summarization.

Neurotic ego defense mechanisms are again fairly common in practice among adults; neurotics are the people with extreme mood swings. These types of defenses have short-term advantages in coping, but can cause long-term problems in relationships, work and adjustment in life, when used as one's primary style of adjustment with the world. These mechanisms include displacement, dissociation, hypochondriasis, intellectualization, isolation, rationalization (making excuses), reaction formation, regression, repression, undoing and withdrawal.

Mature defense mechanisms are mostly used by emotionally healthy adults and therefore considered as mature. Mature defense mechanisms are learnt during the immature stage of development and such defenses have been adapted through the years to optimize success in life and relationships. The use of these defenses enhances pleasure and feelings of control. These defenses help to integrate conflicting emotions and thoughts, whilst still remaining effective. Those who use these mechanisms are usually considered virtuous. These mechanisms include altruism, anticipation, humour, identification, introjections, sublimation and thought suppression. All of the above mentioned type and subtype of defense mechanisms can prevent individuals from experiencing the excessive level of the anxiety, negative effects and socially unacceptable drives such as: Anxiety: anguish, genuine fears and loss of self-esteem, Negative effects: jealousy; bereavement and hostility, 
etc. Socially unacceptable drives: aggressiveness, sexuality, superego's judgments and forbidden impulses (Conte, H.R. \& Plutchik, R., 1995).

Defense mechanisms are no longer considered to be processes employed to cope with against particular impulses or wishes, rather, these mechanisms might also have close relationships with other important human behaviours, functioning and psychological factors (Cooper, 1998). Defense mechanisms have continued to gain acceptance among contemporary researchers and has become a central issue for future researches. The present day shift toward inter-disciplinary research has motivated researchers to understand and investigate the correlation between defense mechanism styles adopted by individuals and their performance and achievements in domains of personal and work life. Present research is an effort to find out the relationship between managerial effectiveness and the patterns of the defense mechanism adopted by the managers working at various levels of management (i.e. junior, middle and senior) in public and private sector organizations.

\section{Managerial effectiveness}

Managerial effectiveness is manager's ability to achieve desired results or in other words managerial effectiveness is how well managers apply their knowledge, skills and abilities in guiding and directing others while working with them. Managerial effectiveness determines whether managers can meet the desired results effectively and efficiently, if they can, their achievements are poised to help the organization gain a competitive edge against competing organizations heading into the future.

An effective manager has a combination of technical, interpersonal and conceptual skills that can make him a successful and useful manager, according to theoretical models of management, technical skills include specialized workability, skilled performance on specific tasks, expertise in a specific technical field of industry and the ability to apply specialized knowledge to tasks and objectives. Interpersonal skills include the ability to work well with various types of personalities to motivate, resolve conflicts, delegate roles and communicate objectives clearly. Whereas conceptual skills are broader and more self-actualized, these skills include the ability to see the organization in the context of its industry. Besides this conceptual skills include the ability to visualize, imagine, think, remember and process information for future course of action based on the ability to analyze and diagnose complex mental and physical situations faced by managers during their day-to-day work life. Present day manager's job is a very complex and intricate combination of conceptual analysis, interpersonal interactions and physical work. While working in the organizations with others, by using various types of conceptual and interpersonal skills, managers have to face situations where they undergo different types of mood swings, anxiety, stress, shame, guilt and embarrassment etc. It is no surprise to say that anxiety is an inevitable part of the professional life of managers which is derived from the personal experiences, interaction with seniors, juniors and co-employees. To understand and manage the relationships of such situations with self and others at work in the organizations, managers should have a technology to cope with the anxiety and stressful situations type of environment. Manager's effective adjustment in anxious and stressful conditions may lead to the effective management of organizations. Individuals may manage the anxious and stressful states of mind by using the technique of defense mechanism. Present study is concerned with examining the interrelationship between the managerial effectiveness and defense mechanism styles adopted and practiced by the managers lworking at different levels of management in the public and private sector organizations.

\section{NEED FOR STUDY}

A comprehensive literature survey had been conducted before initiating this research, no such study has been conducted so far (Especially in Indian context) so the need for conduction of this study is justified. Studying the relationship between defense mechanisms and managerial effectiveness may offer the management philosophers and psychologists a porthole into the manager's unconscious world to find out the styles of their defense mechanism adoption while working at various levels of management. Research findings will also help to understand how these defense mechanisms are related to managerial effectiveness. Facts investigated and disclosed by the research will be helpful and supportive for the managers to use the positive and constructive defense mechanisms and eliminate the undesirable one (by using effective training programmes) to manage their unwanted feelings of guilt, embarrassment, anxiety and shame to ultimately enhance the personal and managerial effectiveness. 


\section{METHOD}

Research was conducted by taking a sample of 234 managers (as subjects) which were working with public and private sector organizations at all the three levels of management i.e. junior, middle and senior level. These subjects were chosen on random basis through available sampling. Subjects so selected were tested for managerial effectiveness and ego defense styles adopted by them by using the research instruments the Defense Style Questionnaire (DSQ-40) developed by Andrews, Singh, \& Bond, (1993) and Index of Managerial Effectiveness devised by Walter W. Hudson (1993). Data collected by using questionnaire method was statistically analyzed by descriptive statistics methods, Pearson's correlation, multivariable regression analysis and independent $t$ test etc. for concluding the findings and results.

\section{TESTS}

Defense Style Questionnaire (DSQ-40) developed by Andrews, Singh, \& Bond, (1993) used as measuring instrument for testing the style of defense mechanism. DSQ-40 is an instrument consists of 40 questions which measures 20 defense mechanisms in terms of three styles: mature, neurotic and immature on the nine-graded likert scale. Cronbach's alpha coefficient has been described for the questions about each satisfactory defense style Andrews, G., Singh, M. and Bond, M.(1993). The psychometric features of the defense styles questionnaire have been examined and acknowledged through different research on different type of samples (n=423) Besharat, M.A. (2009) and Besharat, M.A., Sharif, M. and Iravani, M. (2001).

Index of Managerial Effectiveness (IME) devised by Walter W. Hudson (1993) was used for measuring managerial effectiveness of the sample. The IME scale is designed to measure the way employee perceive their manager or administrator with respect to their managerial effectiveness. Index of Managerial Effectiveness has been created by Walter W. Hudson (1993).

This questionnaire consists of 30 statements which measure the managerial effectiveness. The reliability of the index was found to be $a=0.71$ when tested on different type of samples.

\section{RESULTS}

Among the indices of Managerial Effectiveness, senior managers have a higher mean $(\mathrm{M}=3.64)$ in comparison to middle level managers $(M=1.11)$ and junior managers $(M=1.70)$ and among the indices of defense mechanisms, mature defense style element has a higher mean $(M=5.83)$ in comparison to neurotic defense style element $(M=5.48)$ and immature defense style element $(M=4.41)$. In order to examine the relationship between managerial effectiveness and defense mechanisms among different level of managers, Pearson's correlation was used whose results have been shown in table (1).

Table (1): The Correlation between Managerial Effectiveness at Various Levels of Management and Their Defense Mechanisms Indices.

\begin{tabular}{|c|c|c|c|c|c|c|}
\hline Defense & \multicolumn{2}{|c|}{ Mature } & \multicolumn{2}{|c|}{ Neurotic } & \multicolumn{2}{|c|}{ Immature } \\
\hline $\begin{array}{l}\text { Managerial Effectiveness } \\
\text { among different Level of } \\
\text { Management }\end{array}$ & Correlation & $\begin{array}{l}\text { Meaning } \\
\text { fulness }\end{array}$ & Correlation & $\begin{array}{l}\text { Meaning- } \\
\text { fulness }\end{array}$ & Correlation & $\begin{array}{l}\text { Meaning } \\
\text { fulness }\end{array}$ \\
\hline Junior Level Management & 0.40 & 0.001 & -0.007 & 0.26 & -0.13 & 0.03 \\
\hline Middle Level Management & 0.51 & 0.001 & 0.10 & 0.13 & -0.08 & 0.19 \\
\hline Senior Level Management & 0.26 & 0.001 & 0.09 & 0.17 & -0.25 & 0.001 \\
\hline
\end{tabular}

Table (1), shows that there is a negative and significant correlation between the managerial effectiveness of junior level managers and the immature styles of defense mechanism adopted by them $(\mathrm{r}=-0.13$ and $\mathrm{P}<0.05)$. There is positive and significant correlation between managerial effectiveness of junior level managers and the mature styles of defense mechanisms adopted by them $(\mathrm{r}=0.40$ and $\mathrm{P}<0.05)$ which implies that higher the tendency of mature defense mechanisms among the junior managers higher the affinity towards the managerial effectiveness. The junior managers with higher managerial effectiveness have greater tendency to adopt the mature styles of defense mechanisms whereas managerially non-effective junior managers have tendency to 
adopt immature style of defense mechanism. It is also evident from Table (1) that correlation between managerial effectiveness of junior level managers and the neurotic styles of defense mechanisms adopted by them is not significant $(\mathrm{r}=-0.07$ and $\mathrm{P}>0.05)$.

If we study the relationship between the managerial effectiveness of the middle level managers and their styles of immature and neurotic defense mechanisms then it is found that there is no o significant correlations between these two indices of defense mechanism and managerial effectiveness as shown by the values of correlation between managerial effectiveness and mature styles $(\mathrm{r}=-0.08$ and $\mathrm{P}>0.05)$ and also between managerial effectiveness and neurotic defense mechanism ( $\mathrm{r}=0.10$ and $\mathrm{P}>0.05)$. But the correlation between the managerial effectiveness of the middle level managers and their styles of mature defense mechanism is positively significant as exhibited by the values $(\mathrm{r}=0.51$ and $\mathrm{P}<0.05)$. These results show that higher the tendency of mature styles of defense mechanisms among middle level managers more the managerial effectiveness among them.

The managerial effectiveness of the senior managers and their styles of mature defense mechanism are positively and significantly correlated $(r=0.26$ and $\mathrm{P}<0.05)$ whereas the managerial effectiveness of the senior managers with their styles of immature defense mechanism are negatively correlated as shown by the values $(\mathrm{r}=-0.26$ and $\mathrm{P}<0.05)$. Research results shows that higher the predisposition towards mature styles of defense mechanisms among senior managers, higher is their managerial effectiveness and lesser the managerial effectiveness among them, lesser the trend of adoption for immature style of defense mechanism. There is no significant correlation between senior manager's managerial effectiveness and neurotic style of defense mechanism ( $\mathrm{r}=0.09$ and $\mathrm{P}>0.05)$.

Above mentioned findings clearly show that all the three levels of managers i.e. junior, middle and senior exhibits the positive and significant correlation among the managerial effectiveness and mature style of defense mechanism adopted by them. On The other hand correlation between managerial effectiveness and immature style of defense mechanism adopted by different level of managers was found negative and significant. There was no correlation between managerial effectiveness and neurotic style of defense mechanism.

Table (2): Independent $T$ Test for Comparing the Defense Mechanisms Used by Managerially Effective and Non-Effective Managers Working at Various Levels of Management in Public and Private Sector Organizations.

\begin{tabular}{|c|c|c|c|c|c|c|c|c|}
\hline \multicolumn{2}{|c|}{ Groups } & Frequency & Mean & $\begin{array}{c}\text { Common } \\
\text { Mean }\end{array}$ & $\begin{array}{l}\text { Standard } \\
\text { deviation }\end{array}$ & $\mathrm{t}$ & df & $\begin{array}{l}\text { Signific- } \\
\text { ance }\end{array}$ \\
\hline \multirow[t]{2}{*}{ Mature } & $\begin{array}{l}\text { Managerially } \\
\text { Effective }\end{array}$ & 149 & 6.23 & \multirow[t]{2}{*}{5.83} & 1.26 & \multirow[t]{2}{*}{3.59} & 21 & \multirow[t]{2}{*}{0.001} \\
\hline & $\begin{array}{l}\text { Managerially } \\
\text { Non-effective }\end{array}$ & 72 & 5.63 & & 1.13 & & 9 & \\
\hline \multirow[t]{2}{*}{ Neurotic } & $\begin{array}{l}\text { Managerially } \\
\text { Effective }\end{array}$ & 152 & 5.74 & \multirow[t]{2}{*}{5.48} & 1.26 & \multirow[t]{2}{*}{1.71} & 22 & \multirow[t]{2}{*}{0.08} \\
\hline & $\begin{array}{l}\text { Managerially } \\
\text { Non-effective }\end{array}$ & 74 & 5.44 & & 1.24 & & 4 & \\
\hline \multirow[t]{2}{*}{ Immat ure } & $\begin{array}{l}\text { Managerially } \\
\text { Effective }\end{array}$ & 145 & 4.56 & \multirow[t]{2}{*}{4.41} & 1.10 & \multirow[t]{2}{*}{3.47} & 21 & \multirow[t]{2}{*}{0.001} \\
\hline & $\begin{array}{l}\text { Managerially } \\
\text { Non-effective }\end{array}$ & 72 & 4.10 & & 0.81 & & 5 & \\
\hline
\end{tabular}

To examine the difference between the style of defense mechanisms adopted by the managers who are managerially effective and non-effective managers, independent $\mathrm{T}$ test was used for this purpose, results can be seen from Table (2). Table (2) depicts there is a significant difference between the means of mature style of defense mechanisms used by the managerially effective and non-effective managers $(t=3.59$ and $\mathrm{P}<0.05)$ and it could be expressed that the managerially effective managers $(M=6.23)$ have significantly more mature style of mechanisms than the managerially non-effective managers $(M=5.63)$. Besides, there is a significant difference 
between the means of immature style of defense mechanism used by the managerially effective managers and non-effective managers $(\mathrm{t}=3.47$ and $\mathrm{P}<0.05)$. In fact, the managerially non-effective managers have significantly more immature styles of defense mechanism $(M=4.56)$ than the ones having managerial effectiveness $(M=4.10)$. But there is no significant difference between the means of neurotic style of defense mechanism adopted by the managerially effective managers and the managerially non-effective managers $(t=1.71$ and $P>0.05)$, i.e. there is not a significant difference between the managers who are managerially effective $(M=5.74)$ and managerially non-effective managers $(M=5.44)$ in neurotic defense style.

\section{DISCUSSION}

Managerial effectiveness- among senior managers have a higher mean $(\mathrm{M}=3.64)$ in comparison to middle level managers $(M=1.11)$ and junior managers $(M=1.70)$. This difference in the mean scores of the managerial effectiveness among managers might be the result of development of effective knowledge, skills and attitude by virtue of acquisition of experience while working for long time on different positions from junior manager to middle level and lastly to the senior position of management. Among the dimensions of defense mechanisms, mature defense style element has a higher mean score $(\mathrm{M}=5.83)$ in comparison to neurotic defense style $(M=5.48)$ and immature defense style $(M=4.41)$ adopted by the managers. Difference in the mean scores of different groups of managers clearly exhibits that they have a higher tendency to practice the mature style of defense mechanism. Mature style of defense mechanisms are mostly learnt and adopted during the childhood and practiced during adulthood to develop a healthy adjustment with self and others (Cramer, P., 2000). So to manage the affairs of the organization effectively all the managers might have been using the mature style of ego defense mechanism. Findings of the results have also been approved by the Pearson's correlation analysis. Table (1), shows that there is a negative and significant correlation between the managerial effectiveness of junior level of managers and the immature styles of defense mechanism adopted by them. On the other hand there is positive and significant correlation between managerial effectiveness of junior level of managers and the mature styles of defense mechanisms adopted by them. These findings implies that higher the tendency of mature defense mechanisms among the junior managers higher the affinity towards the managerial effectiveness. The junior managers with higher managerial effectiveness have greater tendency to adopt the mature styles of defense mechanisms whereas managerially non-effective junior managers have tendency to adopt immature style of defense mechanism. It is also evident from Table (1) that there is no significant correlation between managerial effectiveness of junior level of managers and the neurotic styles of defense mechanisms adopted by them. Immature and neurotic types of ego defense mechanisms are not the healthy and useful type of adjustment adopted by the individuals to cope with the anxious and stressful mental situations. According to Vaillant, G.E. (1977) the defense mechanisms adopted under the neurotic and immature styles of defenses are: acting out, fantasy, idealization, passive aggression, projection, projective identification and summarization etc. for immature style of defense mechanism and displacement, dissociation, hypochondriasis, intellectualization, isolation, rationalization (making excuses), reaction formation, regression, repression, undoing and withdrawal for neurotic type of defense mechanism respectively. All these styles of ego defense mechanisms may be instantaneous reliever of anxiety and mental stress but cannot be considered as a healthy and useful method. An unhealthy style of ego-defense mechanism can occasionally prevent the person from the negative effects but in the management of organizational affairs, in long run, this type of adjustment with self and others may result to non-effectiveness. Mature defenses are correlated with better adaptability and compatibility in life. The continuation of work and successful love life are positively correlated with mature defense mechanisms and negatively correlated with immature defense mechanisms. According to Millon, T. \& Grossman, S. (2007) there are significant correlations between anti-social characteristics and extrajection, obsessional characteristics and reaction producing, paranoid features and projection and inactive aggressive features and displacement. Mature styles have significant effect on individual success variable. Viallant have found out that mental health is associated with mature defense mechanisms such as refinement, prediction, sense of humor, etc. individuals who employ acceptable mature mechanisms can cope with stress very well and adaptively respond to conflict. Researchers have established that stress-free working leads to the effective performance and such people will definitely be highly managerially effective. A pilot study shows that emotional disorder is positively correlated with immature defense style and negatively correlated with mature defense style and not correlated with neurotic defense style (Heidarynasab, L., 2006). 
If relationship between the managerial effectiveness of the middle level managers and their styles of immature and neurotic defense mechanisms are compared, then among these categories also, there are no significant correlations between managerial effectiveness and the indices of ego defense mechanism of immature style as well as neurotic defense mechanism. But the correlation between the managerial effectiveness of the middle level managers and their styles of mature defense mechanism is positively significant. These results again show that higher the tendency of mature styles of defense mechanisms among middle level managers more the managerial effectiveness among them. In case of senior managers also there is a positive and significant correlation between the managerial effectiveness and their styles of mature defense mechanism but the managerial effectiveness of these managers is negatively correlated with their styles of immature defense mechanism. So among senior managers also higher the predisposition towards mature styles of defense mechanisms, higher the managerial effectiveness and lesser the managerial effectiveness, higher the trend of immature style of defense mechanism. There is not a significant correlation between senior manager's managerial effectiveness and neurotic style of defense mechanism. Mature defense is seen among the managers who have more abilities and capabilities to outsmart stress and this can increase the chance of being managerially effective. According to Suppes, P. \& Warren, H. (1975) immature defense mechanisms can drive a person into affective fatigue to a great extent, since in most of the mechanisms of this defense style people resort to assimilation, projection and fantasizing; to the extent that the person feels isolated and even loses their identity. Because of this, it's obvious that emotional analysis is parallel with immature mechanisms. A conclusion may be drawn from the above discussion that among all the three levels of managers' i.e. junior, middle and senior of various public and private sector organization, there is positive and significant correlation among the managerial effectiveness and mature style of defense mechanism. On the other hand the correlation between managerial effectiveness and immature style of defense mechanism adopted by different level of managers was found negative and significant. There was no correlation between managerial effectiveness and neurotic style of defense mechanism.

To compare the findings among managerially effective and non-effective managers, $t$ tests has established the findings that there is a significant difference between the means of mature style of defense mechanisms used by the managerially non-effective and effective managers and it could be expressed that the managerially effective managers have significantly more mature style of mechanisms than the managerially non-effective managers. Besides, there is a significant difference between the means of immature style of defense mechanism used by the managerially non-effective managers and the managerially effective managers. Research findings also establish that managerially non-effective managers have significantly more immature styles of defense mechanism than the managerially effective managers. But there is no significant difference between the mealls of neurotic style of defense mechanism adopted by the managerially non-effective managers and the managerially effective managers. Lastly there was no significant difference between the managers who are managerially non-effective and managerially effective managers in their neurotic defense style. The findings of the Research can be understood with the help of explanation that when an emotion becomes too overwhelming for the conscious mind to cope with and express, it is altered and expressed through what are called defense mechanisms. Sigmund Freud (1923) developed the theory, and his daughter Ana Freud (1966) expanded on it, describing defense mechanisms fully and setting forth one of the cornerstone principles. Valliant, G. E. (1992) furthered the discussion on defense mechanisms by stating they should not be thought of as a negative process. They mark the effort of adaptation to continue survival under difficult or threatening circumstances and some defenses like mature styles of ego defense mechanism can even optimize and improve the functioning by protecting the individual from negative effects.

The results show that the majority of managers having higher tendency for mature style of defense mechanisms exhibits the higher degree of managerial effectiveness and vice-a-versa. There is a significant relation between the high levels of anxiety and the symptoms of stress, fatigue and the poor life quality because of non-effectiveness in the work and personal life. When an individual is emotionally fatigued, the sense of empathy and understanding of such a person for self and others is reduced and it affects the work, social and personal life quality (Valliant, G. E. 1994). According to Spitz, R. A. (1961) when the defense mechanisms employed by a person become more immature and neurotic type then the characteristics of depersonalization is seen among such persons. And in this type of situation individual will try to protect himself/ herself ineffectively against anxiety and stress by employing immature mechanisms. For instance, justification is one of 
the immature defense mechanisms which are resultant of tense and irritating situations (Kernberg, P. F., 1994). Under such circumstances a person tries to make the behavior logical, there will be need of ego defense mechanism to get protected from the negative effects. It's clear that there is a stronger possibility that such persons will treat themselves as well as others working with them negatively and lastly results in noneffectiveness. So in long run to get rid of this type of situations, the probability of employing mature ego defense mechanisms increases and neurotic and immature defense mechanisms have a slighter chance and become less a necessity of acting. Therefore it could be said that as long as the person is positive and recognizes the achievements, the probability of employing mature mechanisms increases which confirms the findings.

\section{References}

[1] Andrews, G., Singh, M. and Bond, M. (1993). "The Defense Style Questionnaire," Journal of Nervous and Mental Disease, 246256.

[2] Besharat, M.A. (2009) "Evaluation of reliability, validity and factor analysis of the defense style questionnaire," Contemporary Psychology, 8, printed below, 2009.

[3] Besharat, M.A., Sharif, M. and Iravani, M. (2001) "Relationship between attachment styles and defense mechanisms," Journal of Psychology, 5 (3 (19):289-277.

[4] Conte, H. R. \& Plutchik, R. (Eds.). (1995). Ego defenses: Theory and Measurement. New York: John Wiley \& Sons, Inc.

[5] Cooper, S. H. (1998). Changing notions of defense within psychoanalytic theory. Journal of Personality, 66(6), 947 - 964. 90

[6] Corey, G. (2005). Psychoanalytic therapy. Theory and Practice of Counseling \& Psychotherapy (7th ed., pp. 54-91). Belmont, CA: Brooks/Cole - Thomson Learning.

[7] Cramer, P and Jones, C.J. (2007). "Defense mechanisms predict differential lifespan change in Self-control and Self-acceptance," Joitrnal of Research in Personality, volume 41, Issue 4, Pages 841-855.

[8] Cramer, P. (2000). Defense mechanisms in psychology today: Further processes for adaptation. American Psychologist, 55(6), 637 $-646$.

[9] Freud, A. (1966). The Ego and the Mechanisms of Defense, rev. ed. New York: International Universities Press.

[10] Freud, Sigmund. (1920). Beyond the Pleasure Principle. SE, 18: 1-64.

[11] Freud, S. (1923). The Ego and the Id. SE, 19: 1-66.

[12] Heidarynasab, L. (2006). "Coniparison of defense mechanisms in non-clinical and clinical samples based on normal terms and psychometric questionnaire results based on the Iranian defense styles, (DSQ)" PhD thesis. Tarbiat Modarres University.

[13] Kernberg, P. F. (1994). Mechanisms of defense: Development and research perspectives. Bulletin of the Menninger Clinic, 55(1), $55-87$.

[14] Millon, T. and Grossman, S. (2007). Resohing Difficult Clinical Syndromes: A Personalized Psychotherapy Approach. Hoboken: John Wiley and Sons.

[15] Spitz, R. A. (1961). Some early prototypes of ego defenses. Journal of the American Psychoanalytic Association, 9 , 626 -651.

[16] Suppes, P. \& Warren, H. (1975). On the generation and classification of defence mechanisms.

[17] International Journal of Psychoanalysis, 56, $405-414$.

[18] Vaillant, G. E. (1977). Adaptation to life. Boston: Little, Brown and Company.

[19] Vaillant, G. E.(1992). "Ego mechanisms of defense: A guide for clinicians and researcher, "Washington DC: American Psychiatric Press. 158.

[20] Vaillant, G. E. (1994). "Ego mechanism of defense and personality psychopathology," Journal of abnormal psychology, 103,4450,1994

[21] Vaillant, G. E. (2000). Adaptive mental mechanisms: Their role in a positive psychology. American Psychologist, 55(1), 89-98. 